\title{
Legal Classification of Non-Conforming Bodies in the United States
}

\author{
Brooke English
}

Since the mid-twentieth century, transgender and gender non-conforming people have become increasingly present and visible in the United States. As a result, social and political movements focused on trans issues have cropped up, as evidenced by the rise of bills that aim to restrict access to public facilities based on a person's sex assigned at birth as well as bills that look to expand the scope of genders that are included in the state's demographic measures. Through this shift towards codified definitions of gender, gender loses its status as an intrinsic characteristic. Gender as an identity category is undergoing a transformation that is blending the performative aspects of gender (Butler 1990) with the legal definition of gender. As the stakes associated with the legal definition grow, legal ideas about gender become privileged over performative ideas. In the eyes of the law, gender has become dissociated from the body and is represented instead in the legal documentation of the state.

Furthermore, these pieces of legislation are creating the conditions of possibility by which gender norms can be subverted by creating practically invariable definitions of gender. The delineation of which bodies are allowed in which bathroom in and of itself creates the capability for bodies to be non-normative in these increasingly regulated spaces. This classification of non-normative bodies into reductive categories through legislation is happening in two separate ways. California's Gender Recognition Act creates a normalization of identity through assimilation, simplifying the complexity of non-binary identities to the singular category "non-binary." On the other hand, bathroom bills such as Texas's Senate Bill 6 and North Carolina's House Bill 2 force non-normative bodies into a category based on their sex assigned at birth, which is a frequently inaccurate determiner of gender. In both cases, gender is dissociated from the individual through the same common means: legal documentation.

For my essay on the legal classification of gender non-confirming bodies in the US I completed a critical discourse analysis (Fairclough \& Fairclough 2012) of legislative documents such as Texas's Senate Bill 6, North Carolina's House Bill 2, the Republican National Committee 2016 Platform, and California's Senate Bill 179 through the lens of queer theory and Michel Foucault's concept of psychiatric power. My multiple readings of the legislative bills and documents focused first, on the "spirit" of the law and the bill's intentions, and second, on the specific language used within the documents and how that language specifically creates legal conceptions of gender. While examining the language of each document, I compared 
the ways that gender is seen in the eyes of the law to Judith Butler's ideas of gender as performance (1990) and Gayle Rubin's discussion of normalcy and the charmed circle (1984) to inform my understanding of how gender is recognized in these documents and how this recognition signals a shift towards gender as classification. Finally, I looked at each legislative document to compare the language that is used to find similarities and differences between each bill's definition and classification of gender.

\section{Gender as Classification}

In recent years, judges and legislatures have increasingly used legal documentation as the definer of gender rather than gender expression or physical appearance. In the United States, mid-twentieth century era anti-crossdressing laws, otherwise known as three-piece rules, determined whether or not a person was in violation by determining if they were wearing three or more articles of clothing of the "opposite sex" (Bolich $2008,247)$. The focus of the law here is on the non-normative presentation. The presentation and its difference from gender norms are specifically what are being regulated and criminalized in these kinds of gender-regulatory laws. However, as is the case with bathroom bills, recent legislation only cares about what is listed on a person's legal documentation. No matter what a person's presentation, gender identity, or morphological features may be, gender is defined by what is on that person's driver's license or, as is most cases with bathroom bills, that person's birth certificate. Now, a person is determined to be in violation of a law based on what the birth certificate says. Despite this shift, however, gender performance does remain a factor in the enforcement of these bills as only those with non-normative bodies or presentation have their legitimacy questioned in gendered spaces. In the aftermath of the passing of North Carolina's House Bill 2, several North Carolinians reported concerns of safety and wellbeing due to their gender presentation. Jamie and Sophie Lamkin are two North Carolina natives who are cisgender females, but have experienced harassment in the past for their non-normative expression; they fear that House Bill 2 created an environment in which they could be legally targeted (Petrow 2016). Once again, the non-normative expression is what brings these bodies under scrutiny, but it is the gender marker on the legal documentation that determines whether or not the body is in violation of the law. The gender marker is the only determiner that matters in the eyes of the law.

California's Senate Bill 179, also known as the Gender Recognition Act, takes the issue of legal documentation of gender straight on. The bill seeks to expand the options for gender markers on legal documentation by adding a "nonbinary" option and thus to normalize non-binary identity. Through this expansion, the bill aims to "recognize a person's accurate gender identification" (Atkins and Wiener 2017). However, the process by which the bill expands California's definition of gender reflects assimilatory processes, the idea of the charmed circle (Rubin 1984, 109), and ultimately reduces complex gender identities into a glorified "other" category. California's addition of the third gender category captures non-normative bodies in a way that until now were not seen in the eyes of the law. These non-normative identities are brought into the fold of acceptability in legal recognition as a result of these changes. However, legal recognition does not immediately create social recognition and acceptance. In terms of demographics, non-normative bodies and identities are unable to be captured effectively, as only male and female are listed as options for gender. With the introduction of the non-binary option, nonnormative bodies are now seen, which brings up a whole new set of issues. Insurance policies, gendered prisons, and the ever-important bathrooms are all areas of society that are complicated with the classification of nonnormative identities. For the assimilatory process to be complete, society

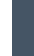

(1) 
must accept and adapt to non-binary identity and expression. Once those conditions are met, non-binary identity becomes a part of the charmed circle, which represents the acceptable behaviors in society. Without this bill, non-normative bodies are classified as either male or female in terms of legal documentation, regardless of characteristics of the individual body, including presentation, morphological features, and personal identity. However, the addition of this third category sifts out the non-conforming bodies from those that fit within binary norms and ironically creates an exclusionary measure in this sense. Without the social support for nonbinary bodies, non-binary people are caught in a paradox where they are legally recognized as non-binary, but still must choose to use either the male or the female bathroom. Rather than acknowledge the complex and expansive galaxy of gender (Vade 2005, 261), the Gender Recognition Act places anyone outside of the binary norms into a separate box which, despite the act's goals, lacks the complexity of non-binary identities: a complexity that cannot truly be captured in legal documentation except when it is captured to fix them as norms.

\section{Shift towards Normalcy}

Despite its good intentions, the goal that the Gender Recognition Act is attempting to achieve is too broad to effectively be completed through the process of assimilation and may not even have a noticeable effect on the experiences of gender non-conforming persons. Regardless of how the legal system sees bodies, the aspects of gender performance are still very much present in general society and gender non-conforming people are still judged and shunned for their presentation. An alternative to the kind of assimilation the Gender Recognition Act is proposing exists in the idea of "genderfuck" (Reich 1992). Genderfuck is a radical gender identity that purposefully blurs elements of the binary norms together to complicate the idea of gender presentation. Rather than conform to societal expectations or exist just at the edge of the charmed circle, genderfuck people push gender performance to an extreme, flying in the face of what is expected. Under either the Gender Recognition Act or any bathroom bill, however, this kind of expression is made illegal and pushes these bodies towards normalization.

The Gender Recognition Act also participates in a different kind of normalization by providing only marginally expanded categorical options. The act streamlines the process for changing a gender marker on legal documentation, removing the need for "any treatment" and replacing the process with an affidavit declaring that they are not lying about their own personal gender identity. For the affidavit to be valid, the document must include an approximation of the phrase: "I, (petitioner's full name), hereby attest under penalty of perjury that the request for a change in gender to (female, male, or nonbinary) is to conform my legal gender to my gender identity and is not for any fraudulent purpose" (De León 2017). This declaration completely dissociates the person's body from the gender marker; the body does not matter as long as a person's intentions are true. However, while the goal of the bill is to allow more freedom in changing the gender marker, the way by which the bill allows this to happen still uses a large amount of control on part of the government. In this sense, the state is governing how people speak about their gender in legal contexts, once again reducing the complexity of gender into a static, trinary set. Furthermore, the use of the personal declaration creates a unique kind of normalization. Whereas the bathroom bills of Texas and North Carolina force non-normative bodies into categories based on their birth certificate, California lets them choose which category they want to be put in while still requiring people to choose. Although the ability to choose the gender marker with minimal hurdles to clear is closer to a less restrictive documentation system, the lack of complexity inherently

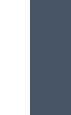


present in all non-binary identities makes this choice ineffectual in terms of accuracy, and yet extremely effective in categorizing and labeling as of yet "unseen" genders and bodies.

While the Gender Recognition Act expands options for adults, this process changes for a person under the age of 18 . The most significant change is that the process for minors requires approval from the person's parents, which echoes parts of the "they're too young to know that they're gay/ bisexual/trans/etc." debate. For the Gender Recognition Act, an 18-year old person's declaration of gender identity is different from and more legitimate than that of a 17 -year old. This part of the bill reflects a pervasive fear of any form of queer representation in media in the United States, as if simple exposure to the mere existence of queer people will create the non-normative identities that are shown. Transgender and gender nonconforming minors must wait until they are 18 , the legally decided time of when they have autonomy over their own gender identity, if they are to make their documents more accurate as the bill aims to do.

The push towards assimilation and normalcy that the Gender Recognition Act represents is unlikely to result in real, tangible change for the transgender and gender non-conforming community as a whole. Much like the anti-bullying policies of yesteryear (Spade 2015, 39-44), this bill will not have a significant impact on the day-to-day lives of transgender and gender non-conforming people and does not sufficiently address the problems that disproportionately affect the community. Disadvantaged (homeless, poor, disabled, etc.) non-binary people will not benefit from this bill in such a way that will solve their most pressing issues. The Gender Recognition Act fails to address the idea of intersectionality and recognize that many people within the transgender and gender non-conforming community have more problems that come as a result of legislation than just gender markers.

\section{Bathroom Bills and the Body}

The fear of queer existence is tacitly acknowledged in the swath of bathroom bills that have cropped up within the past couple of years. Texas's Senate Bill 6 and North Carolina's House Bill 2 create a society in which visibly gender non-conforming bodies cannot legally exist in public spaces. These bills focus on the person's "biological sex," which paradoxically is defined as the "physical condition of being male or female, which is stated on a person's birth certificate" (Kolkhorst 2017). The chosen definition for biological sex ignores the malleable aspects of the body and instead defines a person based on a snapshot of their body on the day they were born; a decision which was primarily motivated by binarist ideas of biological sex. The birth certificate is the way by which physicians and the medical community as a whole categorize bodies. In this sense, a person's gender is invariable; the legislation only cares about the snapshot from the first day of life and it is otherwise blind to the body, ignoring the plethora of inaccuracies that arise between the body and the birth certificate. The rallying cry of supporters of these kinds of bills have been largely concerned with women's privacy and keeping men out of women's restrooms (cf. Campaign for Houston in 2016). Paradoxically, these pieces of legislation allow the mixing of bodies that they claim to prevent. Much like the United States' military's policy of “don't ask, don't tell” as interpreted by Judith Butler (1997), the bills that aim to limit the mingling of normative and non-normative bodies create the very interactions that it aims to prevent. The bill's blindness to the physical characteristics of the body, the characteristics it supposedly defines gender on, result in instances where those characteristics do not align with the traditional binary norms associated with a person's gender as determined by their birth certificate. This is how people who by standards of performativity are viewed as men are legally required to use the space designated for "biologically female" bodies.
SQS

$1-2 / 2018$

54

Queer Mirror

Discussions

Discussions 
Surprisingly, neither Senate Bill 6 nor House Bill 2 make any mention of punishment for an individual entering the "wrong" bathroom, instead focusing on punishments for school districts and cities if they were to allow people of the "opposite [to the bathroom's designated sex] biological sex" use the bathroom (Bishop et al. 2016). Despite these bills' goals of increasing privacy and keeping men out of women's restrooms, as the authors of these bills claim them to be (Herskovitz 2017), there are no expanded punishments for purposefully entering the wrong bathroom. If individual punishments were expanded and enforced, a "show me your papers" society would emerge. Since the proof of one's gender lies in the birth certificate, a person would need to carry their birth certificate with them everywhere to prove that they "belong" in a particular restroom. From the law's perspective, the only element that matters is the gender marker on a person's birth certificate.

Despite the shift towards classifying gender in legal documentation, performativity of gender is not completely obsolete in these moves. As far as enforcement of these bills is concerned, the performativity of gender still comes into play. If someone concludes that a person does not belong in a particular bathroom, the lack of specific consequences for individual violations of the legislation empowers that person to take action against the perceived offender. Bathroom bills are creating a shift towards the diffusion of the power that the psychiatrist once held. Where once the psychiatrist was the determiner of what gender a person is through the power of diagnosis (Foucault 1973), now the power of determining gender has diffused to society as a whole. In terms of enforcement, everyone is now a gender expert. The bathroom bills empower all members of society to question non-normative bodies based on the assumption that the body does not match the documentation. Through this decentralization of power, the psychiatrist is no longer needed to normalize the non- conforming body. Rather, the societal pressure of all gender conforming people will normalize these non-conforming bodies instead.

Furthermore, bathroom bills, particularly House Bill 2, emphasize that a local district cannot provide an accommodation that contradicts the bill. Despite this expansion of state power, the Republican National Committee's 2016 platform condemns the federal government for overreaching its limits of power and aiming to "reshape our schools ... to fit the mold of an ideology alien to America's history and traditions" (Key 2016, 35). Through this statement, the Republican National Committee reduces a political and social issue to a psychological one. Whereas the regulation of bathrooms should only concern the government and society's views on gender, the Republican National Committee characterizes the Obama administration's attempt to protect transgender and gender nonconforming students under Title IX as an attempt to "poison" the minds of Americans and create a new society that is foreign and against what the United States stands for. The logic that the Republican National Committee uses to justify this criticism of the Obama administration is that state governments are more in touch with the people of their state and that those governments should make the decisions. However, following that logic, individual cities and school districts would work more effectively in determining local policy. North Carolina's House Bill 2, which was passed during a special session in less than 12 hours, reversed Charlotte's decision to enact a non-discrimination ordinance that would have provided legal protections based on sexual orientation and gender identity. The processes by which bills like House Bill 2 become law, the conditions that lead to their creation, and the interests that they claim to represent should lead to questions of the authenticity of the bill's authors. Through this kind of questioning, more productive discourse about these bills can begin and inclusive and appropriate legislation can be created.
SQS

1-2/2018

55

Queer Mirror

Discussions

Discussions 


\section{Conclusion}

Viewing bathroom bill legislation through the lens of lived experience is a crucial step in understanding the impact that it has on the transgender and gender non-conforming community. The activism and lobby against legislation like this centers on conventionally attractive, white, and binary transgender people primarily, ignoring the existence of people who do not fit into any specific category. The experiences of people that do not fit within binary standards reflect the need for more comprehensive and wider-reaching legislation. Transgender and gender non-conforming people have more problems than just bathrooms. Much like the gay rights movement, the transgender and gender non-conforming community is falling victim to tunnel vision on one high-profile issue that fails to help the most marginalized within the community.

The conditions that these bills create force transgender and gender nonconforming people to make sacrifices in their identity to escape both figurative and literal violence. In a society in which gender is legally defined by what is on a person's birth certificate, transgender and gender non-conforming people must conform their identities to fit within the norms set out to avoid the violence and scrutiny of gender conforming people. However, this sacrificing of identity is another form of violence that transgender and gender non-conforming people face in today's society. Ultimately, non-normative bodies cannot completely escape both the violence of scrutiny and the violence of self-erasure; they must make a decision between personal safety and personal truth. For this to end, legislation that attempts to normalize non-normative bodies must bring in gender non-conforming voices into the conversation. The Gender Recognition Act lays out definitions for what transgender, non-binary, and intersex mean and gives a brief explanation of discrimination that these groups face. However, every single author of the bills referenced in this article are cisgender and fundamentally cannot understand the struggles and violence that transgender and gender non-conforming people face because of bills like these.

\section{References}

Atkins, Toni \& Scott Wiener. 2017. Gender Recognition Act. Accessed January 15, 2018. https://leginfo.legislature.ca.gov/faces/billTextClient. xhtml?bill_id=201720180SB179

Bishop, Dan, Julia Howard, Paul Stam \& Bob Steinburg. 2016. Public Facilities Privacy \& Security Act. Accessed January 15, 2018. https://www.ncleg. net/Sessions/2015E2/Bills/House/PDF/H2v0.pdf

Bolich, Gregory. 2008. Today's Transgender Realities: Crossdressing in Context. Colorado Springs, CO: Psyche's Press.

Butler, Judith. 1990. Gender Trouble: Feminism and the Subversion of Identity. New York, NY: Routledge.

Butler, Judith. 1997. Excitable Speech: A Politics of the Performative. New York, NY: Routledge.

Fairclough, Isabela \& Norman Fairclough. 2012. Political Discourse Analysis: A Method for Advanced Students (1st ed.). New York, NY: Routledge.

Foucault, Michel. 1973. Psychiatric Power: Lectures at the Collège de France 1973-1974. London, England: Picador.

Herskovitz, Jon. 2017. "Activists, Executives Tell Texas Senate to Ditch Bathroom Bill." Reuters, 2017. https:/www.reuters.com/article/ustexas-lgbt/activists-executives-tell-texas-senate-to-ditch-bathroom-billidUSKBN1A61TQ

Key, Ben. 2016. "2016 Republican National Committee Platform.” Accessed January 15，2018. https://prod-cdn-static.gop.com/media/documents/ DRAFT_12_FINAL[1]-ben_1468872234.pdf

Kolkhorst, Lois. 2017. Women's Privacy Act. Accessed January 15, 2018. http:// www.legis.state.tx.us/tlodocs/85R/billtext/html/SB00006E.htm

Petrow, Steven. 2016. “'Bathroom Bills' Focus on the Trans Community but Could Affect Another Group More.” 2016. https://www.washingtonpost. com/lifestyle/style/bathroom-bills-focus-on-the-trans-community-butcould-affect-another-group-more/2016/04/24/c5026920-0a26-11e6-bfa14 efa856caf2a story.html?utm term $=.3 \mathrm{c} 220196 \mathrm{a} 90 \mathrm{c}$ 
Reich, June. 1992. "Genderfuck: The Law of the Dildo." Discourse: Journal for Theoretical Studies in Media and Culture, 15(1):112-27.

Rubin, Gayle. 1984. Thinking Sex: Notes for a Radical Theory of the Politics of Sexuality. New York, NY: Routledge \& Kegan Paul.

SQS

$1-2 / 2018$

Spade, Dean. 2015. Normal Life: Administrative Violence, Critical Trans Politics, and the Limits of Law. Revised and expanded ed. Brooklyn, NY: South End Press.

Vade, Dylan. 2005. "Expanding Gender and Expanding the Law: Toward a Social and Legal Conceptualization of Gender That Is More Inclusive of Transgender People." Michigan Journal of Gender and Law 11(2): 253316. 